\title{
Abordagem Participativa de Desenvolvimento de Jogos Digitais Educacionais no Contexto Escolar
}

\section{Title: Participatory Approach to the Development of Educational Digital Games in the School Context}

Dyego Carlos Sales de Morais

Centro de Informática - Universidade Federal de

Pernambuco

moraisdcs@gmail.com
Taciana Pontual Falcão

Departamento de Computação - Universidade Federal Rural de Pernambuco

taciana.pontual@ufrpe.br

\section{Resumo}

Educandos que tiveram acesso desde a infância ou possuem facilidade de uso de tecnologias demandam abordagens educacionais inovadoras que atendam às suas características de aprendizagem. As iniciativas recentes vão além do uso de jogos e propõem que os educandos possam construí-los, desenvolver habilidades de design e programação e aprender conteúdos curriculares de maneiras mais atraentes. No entanto, integrar desenvolvimento de jogos digitais ao contexto educacional envolve vários aspectos relacionados ao engajamento estudantil na estrutura de arranjos escolares, incluindo questões gerenciais e pedagógicas de projetos que se inserem nesse meio. Esta pesquisa analisa dois processos escolares de desenvolvimento de jogos e identifica aspectos que promovem o engajamento dos educandos. Os resultados compõem um modelo de desenvolvimento de jogos no contexto educacional.

Palavras-Chave: Engajamento. Design Participativo. Sociointeracionismo. Jogos Digitais Educacionais.

\begin{abstract}
Learners who have had access to digital technologies since childhood or use them easily demand innovative educational approaches that meet their learning characteristics. Recent initiatives go beyond the use of games and propose that students can construct games themselves, developing both design and programming abilities, and learning curricular contents in more engaging ways. However, integrating the development of digital games to the school setting involves several aspects related to student engagement within the structure of educational systems, including management and pedagogical aspects of the projects inserted in such context. This research analyzes two school-based processes of game development and identifies aspects that promote student engagement. Results form a model for game development in educational contexts.
\end{abstract}

Keywords: Engagement. Participatory Design. Socio-interactionism. Educational Digital Games.

Cite as: Morais, D.C.S. \& Pontual Falcão, T. (2018). Participatory Approach to the Development of Educational Digital Games in the School Context (Abordagem Participativa de Desenvolvimento de Jogos Digitais Educacionais no Contexto Escolar). Brazilian Journal of Computers in Education (Revista Brasileira de Informática na Educação - RBIE), 27(1), 132-153. DOI: 10.5753/RBIE.2019.27.01.132 


\section{Introdução}

O uso de tecnologias da informação e comunicação nos espaços escolares pode produzir benefícios no processo de construção do conhecimento, uma vez que pessoas consideradas nativas digitais, que tiveram acesso à tecnologia na infância, constroem conhecimento diferentemente dos imigrantes digitais, que não tiveram este acesso [Mattar 2010; Prensky 2001]. Dessa forma, é importante entender as necessidades dos nativos digitais e a estrutura educacional que precisa ser criada de modo a possibilitar uma inserção adequada de tecnologias no contexto escolar.

Uma das ideias recentes para se reconectar com os educandos vem do interesse deles em jogos digitais. O uso de jogos em processos educacionais obteve resultados positivos, principalmente relacionados ao aumento de engajamento [Wyeth et al. 2013]. No entanto, a introdução de jogos na educação não garante engajamento se for feita como uma ação isolada. Entende-se por engajamento no contexto escolar o nível de envolvimento do educando em atividades escolares [Reeve 2012], isto é, o grau em que o estudante está comprometido com a execução e participa ativamente das atividades escolares [Fredricks et al. 2004]. Fredricks et al. (2004) destacam que o envolvimento dos educandos é muito reativo às mudanças no contexto neste caso, os arranjos sociais da escola e de projetos que incidem nela crescem em importância [Meira e Pinheiro 2012]. Mais do que apenas jogar um jogo, os espaços democráticos que permitem autonomia [Kanthan 2011; Parsons and Taylor 2011], encorajando a colaboração [Kanthan 2011] e a participação ativa [Parsons and Taylor 2011], são fundamentais para o engajamento dos educandos.

Nesse sentido, emergem algumas iniciativas que propõem não só o uso de jogos na educação, mas a construção destes pelos educandos. Estas iniciativas podem ser interpretadas como uma atualização às ideias originais do construcionismo [Papert e Harel 1991], com a ampla gama de possibilidades trazidas pelas tecnologias atuais, como o acesso facilitado à programação através de ambientes de desenvolvimento com linguagem visual baseada em blocos e, consequentemente, a possibilidade de modificação de software em diferentes níveis. Educandos engajados em projetos desse tipo têm acesso a diversos saberes, desde conteúdos curriculares, necessários para a concepção de narrativa dos jogos até conteúdos técnicos de design e programação.

A presente pesquisa analisou dois processos de desenvolvimento de jogos digitais por estudantes, ambos baseados em contextos escolares, com o objetivo de investigar quais aspectos dos processos e do ambiente escolar promovem o engajamento dos educandos. Os resultados serviram de evidências e insumos importantes para modelar um processo de desenvolvimento de jogos digitais nas escolas, incluindo ações docentes e gerenciais, contribuindo para propor arranjos inovadores para projetos similares aos investigados [Morais et al. 2017].

Neste artigo, inicialmente, apresentam-se conceitos de jogos digitais aplicados à educação e pesquisas atuais acerca de engajamento em processos educacionais. Em seguida, são apresentadas as configurações em que a pesquisa ocorreu, explicando a metodologia de coleta e análise de dados. Após isto, apresentam-se os aspectos encontrados para promover o engajamento em configurações dessa natureza, seguido pelo modelo construído a partir desses resultados. Conclui-se indicando como isso se desenvolverá em trabalhos futuros.

\section{Jogos Digitais na Educação}

Para que a aprendizagem seja atraente para o atual público escolar, são necessários recursos interativos semelhantes aos que os educandos estão familiarizados em suas rotinas, fazendo com 
que se interessem pelos conteúdos e se engajem nas atividades propostas [Prensky 2001]. Dentre esses recursos, a aplicação de jogos digitais em processos de aprendizagem é cada vez mais recomendada [Prensky 2001], já que a geração atual de educandos tem características enraizadas na sociedade digital contemporânea e acesso fácil a uma variedade de jogos digitais. Às vezes, chamados nativos digitais [Prensky 2001], essas crianças têm contato com a internet e a tecnologia digital desde que nasceram. Elas são ativas, criativas e pensam e se expressam de maneiras não-lineares, em parte devido a sua imersão no mundo digital [Mattar 2010, Prensky 2001].

Existem duas abordagens gerais para integrar os jogos digitais nos processos de aprendizagem:

(i) abordagem instrucionista, que consiste em promover a utilização de jogos pelos educandos, e desenhar conteúdo ou competências educacionais a partir desse uso; e

(ii) abordagem construcionista, que consiste em prover meios para que os educandos construam jogos, promovendo sua criatividade e autonomia.

Freire (2005) critica a didática que dá base ao instrucionismo, alertando que o educador deve romper com as práticas dessa "educação bancária", na qual se posiciona apenas como um depositador de conhecimentos que enxerga os educandos apenas como receptores. Essa forma de educação, segundo o mesmo autor, reflete a sociedade opressora e a "cultura do silêncio", não dando espaço para o diálogo e a criatividade. $O$ educador deve passar a compor sua pedagogia fundada na participação e autonomia do educando, pois, dessa forma, a educação ganha relevância como instrumento de compreensão da realidade social e do diálogo que propicia a reflexão crítica sobre o mundo.

Para Freire (2005), todas as pessoas possuem conhecimentos que diferem uns dos outros, mas que são igualmente importantes no processo de compreensão e transformação da sociedade. Para Vygotsky (1989), os sujeitos têm formas de construção de compreensão diferenciadas e isso é importante no processo de construção de significado colaborativo. Percebe-se, portanto, uma congruência entre Freire e Vygotsky e utiliza-se do arcabouço teórico da psicologia sóciohistórica para entendimento da participação de sujeitos em atividades colaborativas e dialógicas no contexto escolar.

Segundo Vygotsky (1989), principal autor da psicologia sócio-histórica, é por meio das interações sociais que ocorre o processo de internalização de significados que levam ao desenvolvimento humano ou à aprendizagem. Este processo é mediado por instrumentos e signos, que atuam no nível interpsíquico do sujeito, ao socializar conhecimentos, e no nível intrapsíquico, ao dar significado a construções coletivas e internalizar novos conhecimentos. Nesse sentido, essa pesquisa faz uso dos construtos de Vygotsky (1989) para entender a atuação do professor mediador na escola, enquanto locus cultural de aprendizagem e mais especificamente a Zona de Desenvolvimento Proximal (ZDP). Para entender a ZDP é necessário saber que ela possui dois níveis: nível de desenvolvimento real (retrospectivo) e nível de desenvolvimento potencial (prospectivo). O nível de desenvolvimento real é o nível no qual o aprendiz já chegou. Nível de desenvolvimento potencial é aquele que o sujeito está próximo de alcançar, por exemplo quando aprendizes individualmente não conseguem manusear objetos, mas conseguem com ajuda e mediação de outras pessoas mais experientes, de modo que se apropriem dos conhecimentos construídos em grupo e consigam utilizar os objetos sozinhos posteriormente [Vygotsky 1989].

As metodologias de desenvolvimento de jogos digitais educacionais presentes na literatura, como a apresentada por Zin et al. (2009) com foco em ensino de História, tendem a focar no design instrucional e não focam na participação, autonomia e colaboração dos usuários finais durante a produção do jogo, deixando para esses usuários apenas a participação periférica 
com ideação prévia e testes de usabilidade e/ou jogabilidade após o desenvolvimento. O presente trabalho centra-se na abordagem construcionista, com participação ativa de educandos durante todo o processo de desenvolvimento. Ao construir seus próprios jogos, os educandos aprendem sobre o processo (design do jogo, programação, design gráfico) e sobre os conteúdos do jogo.

O construcionismo de Papert e Harel (1991), originalmente, relaciona o uso do computador como máquina para produzir conhecimento. Quando uma criança constrói um jogo digital - algo difícil de se conseguir quando Papert introduziu o construcionismo - ele/ela deve, como sugeriu Papert, ensinar a máquina. Eles têm que informar ao computador como cada personagem se comporta e definir a narrativa do jogo. O computador é uma ferramenta que permite que a criança construa um jogo, enquanto, muitas vezes, de forma implícita, ela aprende lógica, matemática, física durante a programação e outros assuntos que podem estar envolvidos na narrativa do jogo. Hoje em dia, a tecnologia evoluiu até um ponto em que as ferramentas de programação visual (por exemplo, Scratch, Stencyl e AppInventor) permitem que programadores principiantes criem um produto, ampliando possibilidades para as aprendizagens por meio de construção.

Sendo este produto um jogo, espera-se ainda mais engajamento, dado o apelo para crianças e adolescentes. Um dos objetivos de integrar jogos aos processos educacionais é tornar tais processos tão divertidos e atraentes quanto os jogos, nas opiniões das crianças. No entanto, o contexto sendo o ambiente escolar com suas regras e demandas tradicionais, produz desafios sobre o efetivo engajamento dos aprendentes.

\section{Engajamento em Processos Educacionais}

De um modo geral, o engajamento refere-se à decisão de participar de atividades e ao nível de compromisso envolvido nesta decisão [Lave e Wenger 1991]. No contexto educacional, Fredricks et al. (2004) apresentam três dimensões do engajamento:

- comportamental (conduta e nível de participação em atividades de sala de aula e extracurriculares, tanto acadêmicas quanto sociais);

- emocionais (sentimentos em relação à escola, professores e colegas, que podem criar um sentimento de pertencimento à comunidade escolar); e

- cognitiva (compreensão dos conceitos envolvidos na atividade, desejo de aprender e ir além das demandas intelectuais, buscando desafios, auto-regulação da aprendizagem).

Essas três dimensões são entrelaçadas. A análise deste artigo foi baseada em três aspectos do engajamento identificados na literatura, relacionados com essas dimensões propostas por Fredricks et al. (2004) e congruentes com nossos dados: interesse em participar, colaboração e autonomia.

O interesse na participação é o indicador mais direto de engajamento, profundamente relacionado com a definição de compromisso comum em si e com o engajamento comportamental [Fredricks et al. 2004]. A participação ativa nas atividades da sala de aula pode ser vista como evidência da motivação e envolvimento dos educandos nos processos de aprendizagem [Parsons e Taylor 2011, Reeve et al. 2004].

A colaboração relaciona-se ao engajamento emocional [Fredricks et al. 2004], no sentido que as relações entre pares e educadores desempenham um papel importante e podem afetar a aprendizagem [Lanasa et al. 2009, Willekens e Gibson 2010]. Um ambiente solidário e coletivista com um mínimo de conflito pode encorajar o envolvimento dos educandos e promover melhor desempenho acadêmico [Sagayadevan e Jeyaraj 2012]. Atividades colaborativas que estimulam a interação entre pares e educadores, trocando ideias e contribuindo 
com opiniões e ações, são fundamentais para criar um ambiente propício ao engajamento dos educandos [Kanthan 2011].

Por último, mas não menos importante, a autonomia está intimamente relacionada com a dimensão cognitiva de engajamento [Fredricks et al. 2004]. Estudantes autônomos são capazes de conduzir elementos de seu processo de aprendizagem, como como realizar uma determinada tarefa [Parsons e Taylor 2011, Reeve et al. 2004]. Eles buscam informações e recursos para si próprios para realizar suas atividades [Jang 2008, Kanthan 2011]. O sentimento de ser capaz de trabalhar de forma autônoma pode desenvolver a motivação intrínseca dos educandos para realizar suas atividades [Zepke et al. 2010].

\section{Contextos e Metodologia}

Esta pesquisa foi realizada em dois cenários em que educandos do ensino médio desenvolvem jogos digitais. Todos os educandos envolvidos nesta pesquisa foram voluntários e tiveram sua participação formalmente autorizada por responsáveis legais, através de um termo de consentimento livre e esclarecido. Todos os nomes foram alterados para garantir o anonimato.

\subsection{Cenário 1: Escola de Ensino Médio com Curso Técnico}

O primeiro cenário é uma escola pública de ensino médio integrado com um curso técnico de desenvolvimento de jogos digitais. Os educandos devem escolher se gostariam de ter o papel de designer ou programador na seleção de entrada na escola. Os educadores definem os temas e, no primeiro ano, o briefing dos jogos. Os jogos são desenvolvidos durante as aulas, com o apoio dos educadores, em grupos formados de acordo com as preferências dos educandos. Os educandos são encorajados a realizar pesquisas com usuários quando os jogos envolvem populações específicas (por exemplo, um projeto sobre diabetes). Eles também são orientados por professores e incentivados a participar de competições de desenvolvimento de jogos, como Global Game Jam e SBGames. O objetivo da escola é que os educandos possam seguir uma carreira no desenvolvimento de jogos e/ou realizar cursos de graduação relacionados a design e computação. A escola possui uma abordagem pedagógica que possibilita seu reconhecimento pelos educandos como local de aprendizagem, socialização e diversão.

\subsection{Cenário 2: Projeto de Pesquisa com Intervenções em Escola de Ensino Médio}

O segundo cenário é uma escola pública de ensino médio, que funciona em horário integral no modelo tradicional, exceto em horários semanais pré-estabelecidos, cujo tempo é cedido sem metodologia pré-determinada, a projetos de iniciação à docência e iniciação científica da Universidade Federal Rural de Pernambuco. Um desses projetos de pesquisa é o DEMULTS, que investiga as relações entre aprendizagens de conteúdos curriculares e tecnologia dentro de um processo de desenvolvimento de jogos digitais educacionais, e que ocorre em ciclos anuais desde 2012. Com o objetivo de desenvolver jogos que incluem conteúdos curriculares, mas que também são divertidos, o DEMULTS adota o design participativo [Bødker et al. 1995] e a programação pelo usuário final [Lieberman 2006], à medida que os educandos projetam e desenvolvem jogos, cujo público-alvo são eles próprios e outros educandos de perfil similar. Por se embasar na abordagem do design participativo, os educandos possuem mais poder de tomada de decisão no design dos jogos, e os colaboradores da equipe do DEMULTS são ajudantes desse processo. Por se utilizar a programação pelo usuário final, os educandos conseguem desenvolver seus jogos sem uma formação científica computacional, com estruturas de programação que podem ser extendidas e modificadas. De acordo com Morch (1997), isso pode ser feito através de: customização (usuários modificam opções pré-definidas); integração (usuários conectam 
componentes pré-definidos para criar e/ou modificar o sistema); e extensão (usuários inserem uma nova funcionalidade usando uma linguagem de programação - visual ou textual).

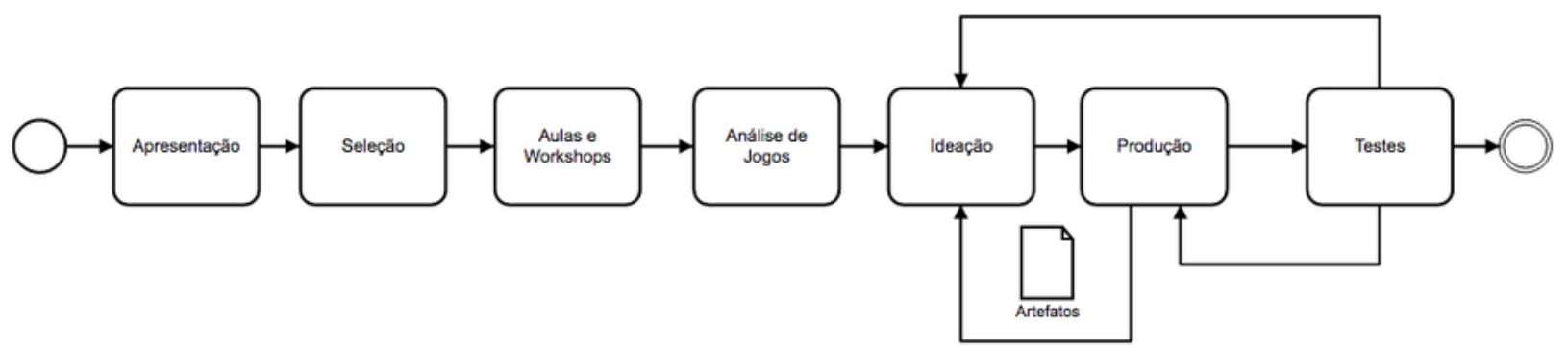

Figura 1: Etapas observadas do processo DEMULTS.

Conforme mostra a Figura 1, o ciclo do DEMULTS inicia-se com a apresentação do projeto na escola campo, seguida de formulário para seleção e entendimento do perfil dos educandos (futuros participantes). Após a seleção, os educandos são divididos em dois grupos, de acordo com suas preferências e habilidades: programadores e designers. Todos têm algumas aulas e workshops sobre ferramentas de desenvolvimento e conceitos básicos de jogos digitais (mecânica, personagens, narrativa, etc.). O objetivo dessas aulas é dar aos educandos uma ideia geral das ferramentas e iniciá-los no processo de desenvolvimento. Espera-se que eles aprendam muito mais ao longo do restante do ciclo, através da prática e interação com colaboradores. Após esses encontros iniciais, cada grupo (programadores e designers) recebe treinamento sobre as respectivas ferramentas de software que estarão usando para desenvolver o jogo. Os programadores são apresentados ao ambiente Stencyl para programação por usuários finais, enquanto os designers conhecem a ferramenta Inkscape para criar cenários e personagens de jogos. Depois disso é feita análise de jogos relacionados à temática do jogo que será desenvolvido. Durante a maior parte de cada ciclo DEMULTS, programadores e designers, educandos e educadores, interagem para desenvolver um jogo educacional digital utilizando artefatos mediadores e com ciclos entre produção e ideação, até que se chegue à fase de testes com usuários. Cada ciclo DEMULTS (12 meses) visa uma matéria específica, e cada equipe deve escolher um item curricular dentro desse assunto para integrá-lo na narrativa do jogo. No ciclo do DEMULTS investigado neste trabalho, as matérias abordadas nos jogos foram português, com a temática de gêneros literários, e matemática, com a temática de trigonometria.

\subsection{Coleta e Análise de Dados}

Os dados foram coletados através de entrevistas semi-estruturadas e observações. No cenário 1, foram realizadas 10 horas de observação não-participante em aulas de design e programação, e entrevistas foram realizadas com quatro educandos e dois educadores. No cenário 2, a observação participante foi realizada de agosto de 2015 a julho de 2016 em reuniões de uma hora e meia, uma vez por semana, na escola. Quatro estudantes que participaram de ciclos anteriores do projeto foram entrevistados. Enquanto no cenário 1 as observações foram realizadas exclusivamente pelo primeiro autor deste artigo, no cenário 2 , toda a equipe do projeto DEMULTS, que inclui o autor deste trabalho, colaborou com notas de campo da observação participante, o que justifica a maior parte dos dados serem extraídos do segundo cenário. Este grupo era formado por duas professoras universitárias, um estudante de pósgraduação e quatro estudantes de graduação. Dezesseis educandos participaram dos ciclos DEMULTS analisados.

Uma análise qualitativa do conteúdo das entrevistas transcritas e das notas de campo foi realizada para descobrir quais aspectos engajam os educandos nos processos de desenvolvimento de jogos digitais em contextos escolares. A análise foi realizada considerando 
os três indicadores de engajamento selecionados da literatura e encontrados nos dados: autonomia, colaboração e interesse na participação.

\section{Aspectos Promotores de Engajamento}

A partir da imersão do pesquisador em contextos escolares com práticas pedagógicas de desenvolvimento de jogos digitais por educandos de ensino médio, observaram-se as etapas dos processos, os artefatos mediadores utilizados e aspectos relacionados ao engajamento dos educandos, sendo os resultados mais relevantes advindos de aspectos promotores de engajamento.

No DEMULTS, foram identificados vários casos de educandos que se interessaram tanto pelo conteúdo de programação que estudavam, independentemente, em casa, e desenvolveram jogos externos ao projeto durante o ciclo de que participavam. Um deles foi Jonatas, que desenvolveu um jogo à parte "por diversão e para aprender" nas palavras dele, denotando um engajamento indicado pelo educando julgar divertida a atividade de programar um jogo próprio. Um outro educando de um ciclo anterior ao analisado deu o seguinte depoimento:

"antes do brainstorm eu já estava pesquisando como trabalhar com o Stencyl. É certo que teve os workshops na escola. Mas quando chegava em casa às vezes eu ia ver como trabalhar com o Stencyl... tentar criar alguns jogos não relacionados com o que a gente tava fazendo, mas por experiência." educando programador do DEMULTS (ciclo anterior)

Nesses exemplos, percebe-se o engajamento comportamental, pois é explicitado o envolvimento dos educandos no projeto, e o engajamento cognitivo, pois explicitam o investimento intrapsíquico do educando no processo de aprendizagem, isto é, o esforço feito pelo educando para alcançar a compreensão do conteúdo em uma área específica de estudo.

Os engajamentos comportamental e emocional são percebidos quando os educandos se apropriam do processo de que estão participando, fazendo sugestões sobre o artefato em construção pelo grupo, seja o jogo em si ou um artefato mediador, a exemplo de uma educanda que propôs o uso de storyboards como artefato mediador do processo do DEMULTS em um ciclo anterior [Morais et al. 2014; Morais et al. 2015). É importante mencionar que isto só é possível em um contexto democrático, com educadores conscientes de que o educando é o centro do processo de ensino-aprendizagem.

Os fatores que levam a engajamento estão relacionadas a conceitos extraídos dos dados em forma de categorias que levam a autonomia, colaboração e participação ativa no contexto escolar. Essas categorias são descritas nas seções seguintes.

\subsection{Autonomia}

Trabalhar de forma autônoma através de um arranjo social democrático foi considerada uma condição necessária para os processos de desenvolvimento de jogos nas escolas, considerando as características de aprendizagem dos nativos digitais. Os aspectos que promovem a autonomia nos processos analisados foram: escolhas democráticas; abordagem por perguntas e desafios; ambiente de programação adequado; e prazos bem definidos.

\subsubsection{Escolhas democráticas}

Em ambos os cenários, o engajamento foi maior quando os temas, a mecânica e a narrativa dos jogos foram definidos pelos educandos. No DEMULTS, os educandos escolhem o tópico específico dentro de um assunto escolar, através de discussão seguida de votação, além de 
escolherem o local do encontro dentro da escola (pátio, biblioteca, sala de aula e sala de informática), conforme os seguintes relatos.

"Houve uma diferença no discurso (sobre a narrativa do jogo) dos educandos para o discurso de Paula (colaboradora de design). Mas ao final um educando confirmou o discurso de Paula, afirmando que foi feita uma votação." - Diogo, pesquisador no DEMULTS (fase de produção)

"Após o momento de socialização, eles tiveram os 5 minutos finais para discutirem qual das ideias propostas seria a melhor para se tornar oficial, ou se eles teriam condições de unir as duas propostas. Pelo que pude perceber, [os grupos de] Português e Matemática preferiram unir as duas narrativas apresentadas por cada grupo em uma só de Português e uma só de Matemática." - pesquisadora gerente no DEMULTS (fase de ideação)

"Voltamos para o pátio. A gestora disse que a biblioteca estava interditada por conta da quantidade de livros a serem registrados (algo assim). Ofereceu uma sala mas os educandos recusaram por causa do cheiro e pediram para ficar no pátio." - Thaís, pesquisadora no DEMULTS (fase de produção)

Colocar os educandos em locais de decisão cria um ambiente democrático que aproxima o modelo escolar do sócio-interacionismo de Vygotsky (1989), segundo o qual a escola é um lugar cultural para o desenvolvimento do sujeito, além de ser congruente com a crítica de Meira e Pinheiro (2012) ao modelo tradicional de aula, com exposição de conteúdos e pressuposição de que a detenção do que é correto sobre a melhor forma de se aprender algo está unicamente com o professor. As evidências mostram que a escola pode voltar a ser inovadora, ao modificar seus arranjos sociais, possibilitando autonomia e colocando os educandos no centro do processo de ensino-aprendizagem.

\subsubsection{Abordagem por perguntas e desafios}

Outra maneira de promover o sócio-interacionismo foi identificada na análise da interação entre educadores e educandos. Quando o educador era perguntado sobre algo, observou-se que incentivar educandos com perguntas, evitando respostas e ordens diretas, foi um bom método para fomentar a autonomia dos educandos.

"[...] quando Jonatas (educando programador de Matemática), usando linguagem técnica, explicou a Diogo (educador/pesquisador) o que iria codificar. Diogo respondeu: "certo. . . acho que tem um jeito mais fácil, mas faça ai do seu jeito”. E Jonatas partiu para a codificação.” - Thaís, pesquisadora no DEMULTS (fase de produção)

"Esse momento, expliquei a Jonatas os condicionais: if, otherwise do Stencyl. E o uso de um atributo booleano. Deixei ele fazer através de um atributo booleano, até que ele viu por si só que estava criando trechos de códigos desnecessários. Através de um jogo de perguntas meus Jonatas chegou a melhor forma (com menos linhas de código). Pedi para que ele me explicasse depois e ele conseguiu explicar, tanto o funcionamento de condicionais como $o$ de variáveis booleanas." - Diogo, pesquisador no DEMULTS (fase de produção)

Outra abordagem utilizada foi observada quando um colaborador/educador de design gráfico demonstrou a alguns educandos, usando o software, como desenhar facilmente uma tartaruga, para então apagar o que acabara de fazer e desafiar os educandos a fazê-lo. Por fim, uma outra abordagem bem-sucedida identificada foi observada quando o educador solucionava 
um problema a pedido de educandos e, sem apagar nem pedir que os educandos refizessem, pedia aos educandos que explicassem como o problema foi solucionado e, a partir daí, ajudavaos para que eles fizessem adaptações à sua solução, se aplicável.

A realização de atividade prática antes de exposição teórica e a mediação do educador sem impor ou dar respostas, mas fazendo perguntas para que o educando construa as respostas autonomamente, são abordagens pedagógicas em aproximação à teoria de aprendizagem sociointeracionista e podem viabilizar engajamento por meio de autonomia. Percebeu-se que isto aumenta a independência dos educandos, fazendo-os pensar em suas próprias soluções, empregando suas habilidades. Muitas vezes, incitando e não respondendo diretamente, é suficiente (e mais eficiente para aprender) em um processo de solução de problemas.

\subsubsection{Ambiente de programação adequado}

Um ambiente de programação com feedback imediato, boa usabilidade e permissão de modificação de software em diferentes níveis pelo usuário final [Mørch 1997] é crucial para dar aos educandos a possibilidade de desenvolver suas habilidades de programação de forma autônoma, conforme relatos:

"Com o decorrer da aula, à medida que os educandos iam conseguindo inserir mais funcionalidades, a motivação foi crescendo. Havia uma satisfação muito clara dos educandos (percebida nos comentários e nas expressões faciais sorridentes e fascinadas) a cada nova funcionalidade que eles conseguiam acrescentar. O feedback imediato da ferramenta (insere, testa, vê o resultado) facilitou muito esse processo." - Thaís, pesquisadora no DEMULTS (aula de Stencyl)

"Jonatas falou sobre um tipo de grupo de atores do Stencyl que não colide com ninguém e falou ainda que isso poderia servir para uma imagem que fica passando, por exemplo. Demonstrando conhecimento da ferramenta $e$ contexto para uso de determinada funcionalidade. Percebi que ele anda fazendo bastante código de eventos e bem menos utilização de behaviors (códigos de terceiros) que antes. Isso também demonstra uma certa autonomia e confiança para criar seus próprios códigos. Só precisei guiá-lo no foco das atividades a serem feitas e ele executou todas. Quando surgiram dúvidas ou melhores formas de fazer algo, eu o auxiliava." - Diogo, pesquisador no DEMULTS (fase de produção)

A extensão do software é um indicador particularmente importante da autonomia do educando, não só no processo de desenvolvimento do jogo, mas também na capacidade de desenvolver código próprio, abrindo o caminho para futuros projetos de programação.

\subsubsection{Prazos bem definidos}

Do ponto de vista muito mais prático, mas não menos importantes, os prazos bem definidos foram bastante impactantes sobre a produtividade autônoma dos estudantes. Quando confrontados com uma data fixa para completar uma determinada fase do processo, os educandos se comprometeram a estabelecer um escopo de jogo viável considerando suas habilidades técnicas. Por exemplo, ao discutir os prazos, um educando sugeriu usar apenas batatas como personagens do jogo, porque já haviam sido desenhadas pelos designers, em vez de buscar a ideia que estava em discussão, de ter vários mini-jogos com personagens diferentes. O estabelecimento de prazos os ajudou a focar e encontrar soluções viáveis, o que é uma habilidade de gerenciamento importante. 


\subsection{Colaboração}

Mais do que uma necessidade de alcançar metas, a colaboração em ambientes educacionais permite o aprendizado mútuo através do intercâmbio de conhecimento, no qual uma pessoa mais avançada pode ajudar um parceiro em seu desenvolvimento pessoal (como discutido por Vygotsky através do conceito de Zona de Desenvolvimento Proximal [Vygotsky, 1989]). Os principais aspectos promotores de colaboração identificados nos processos foram: grupos pequenos; tarefas in loco; prazos bem definidos; auxílio de educador na gestão; e colaboradores que dominem conteúdos curriculares e habilidades técnicas.

\subsubsection{Grupos pequenos}

Como na maioria dos contextos educacionais, mesmo em projetos de pesquisa como o DEMULTS, há um pequeno número relativo de educadores para um número maior de educandos. Observou-se que é muito mais provável que um ambiente de aprendizagem sociointeracionista seja bem-sucedido - ou mesmo viável - se os educadores puderem colaborar com pequenos grupos de educandos.

"estávamos mais próximos da equipe, e muitas perguntas nos foram feitas, $e$ dúvidas foram tiradas." - Rafael, educador de programação do DEMULTS (workshop de ideação com um grupo pequeno de educandos, que faltaram ao encontro oficial)

Além dessas evidências positivas para a colaboração quando se tinha uma proporção menor de educandos/educador, a quantidade de educadores se mostrou insuficiente em outros momentos no DEMULTS, a exemplo do seguinte relato:

"As duas não tiveram nenhuma supervisão de expert e alternaram momentos de foco e dispersão, ouvindo música, dançando, etc." - Thaís, pesquisadora no DEMULTS (fase de produção)

Com menos educandos, a proporção de educandos/colaborador fica mais próxima do ideal e obtém-se maior engajamento, já que se tem mais atenção e mais tempo disponível para suporte a cada educando. Com isso, fica mais fácil entender o processo de aprendizagem de cada educando e fazer intervenções didático-pedagógicas mais próximas ao sociointeracionismo.

\subsubsection{Tarefas in loco}

Os educandos apresentaram grandes dificuldades na realização de tarefas quando fisicamente separados. Como todas as tarefas eram passadas para pequenos grupos, eles deveriam colaborar além do horário das reuniões presenciais, principalmente através de tecnologias de comunicação, durante a semana. No entanto, apesar dos canais de comunicação disponíveis (no DEMULTS em particular, o Facebook e o Whatsapp foram os mais populares), a colaboração à distância não obteve pleno êxito neste ciclo do DEMULTS, ao contrário de ciclos passados. No cenário 1, os educandos preferiram ir à escola em horário extra, incluindo sábados, para trabalhar juntos e com educadores, conforme relato:

"E sempre quando a gente tá aqui ou em casa, acontece alguns probleminhas que a gente não consegue. [risos] E os professores nos ajudam, tornam muito mais fácil e rápido. A gente gosta tanto que abrem o laboratório agora dia de sábado quando tem projeto e o laboratório tá lotado." - educando de programação da escola de nível médio-técnico integrado

Nesse sentido, percebe-se um reconhecimento da importância da escola pelos educandos como um ambiente estruturado pela cultura como um locus cultural para desenvolvimento do sujeito [Vygotsky 1989]. 


\subsubsection{Prazos bem definidos}

Além de promover a autonomia, os prazos bem definidos também contribuíram para fomentar a colaboração. Exemplos de observações de colaboração foram majoritariamente em situações nas quais o prazo para finalização das atividades estava próximo de terminar, como no final da etapa de produção e em atividades com prazos definidos para o mesmo dia, como workshop de ideação e na ideação em si, conforme relato a seguir.

"Os educandos queixaram-se do pouco tempo para cada atividade, mas acho que 'time pressure' acaba sendo positivo. Os educandos se sentem desafiados a produzir naquele curto espaço de tempo e acabam ficando mais focados. Lucca (colaborador de design) foi rígido (mas de forma amigável) com o tempo e isso funcionou." - Thaís, pesquisadora no DEMULTS (ideação)

Entende-se que a pressão do tempo faz com que a interação dos educandos seja direcionada ao trabalho a ser feito coletivamente, promovendo tanto autonomia, quanto colaboração.

\subsubsection{Auxílio de educador na gestão}

No cenário 2 (DEMULTS), embora os educandos tentassem se organizar para o desenvolvimento eficiente do jogo, a necessidade de ajuda na gestão das atividades era evidente. Um dos educadores assumiu o papel de gerente, distribuindo atividades de acordo com as habilidades dos educandos e verificando seus progressos, conforme relatos a seguir.

"Leon (educando designer de Matemática) ressaltou que a falta de divisão do trabalho têm prejudicado a equipe. Esse é um problema que não tem afetado o grupo de Português que tem uma expert/colaboradora muito experiente em desenvolvimento de jogos (Paula) dando suporte integral." - Rafael, educador de programação do DEMULTS (fase de produção)

"dividi o pessoal de design em pequenos grupos de acordo com a facilidade de produção e o desempenho deles." "Como os personagens são a parte delicada do jogo e requerem SpriteSheet, deixei Paulo (educando designer de Português) responsável por eles, já que ele mexe há 1 ano e tem visivelmente mais experiência que os demais." - Paula, colaboradora de design do DEMULTS (fase de produção)

Importante mencionar que isso não foi planejado no projeto, o que deu aos educandos bastante autonomia, mas a equipe percebeu uma falta de maturidade para realizar o trabalho sem ajuda organizacional. Provavelmente, com o tempo, os educandos seriam menos dependentes desse suporte para uma colaboração efetiva. Esse pressuposto é respaldado pelo cenário 1, onde os educandos passam três anos imersos em um modelo de processo de desenvolvimento de jogos e têm a oportunidade de desenvolver suas habilidades de autogestão. Eles escolhem representantes para design e programação em cada grupo, para facilitar a colaboração, e são capazes de fazê-lo de forma mais autônoma ao passar do tempo.

\subsubsection{Colaboradores que dominem conteúdos curriculares e habilidades técnicas}

Apesar de serem encorajados a ser autônomos e exploratórios, os educandos demonstraram a necessidade de ajuda dos educadores com conteúdos conceituais e técnicos. Um educando do cenário 1 declarou:

"Eu gosto daqui, porque temos apoio dos professores. Por exemplo: a gente precisa fazer um jogo. Dá pra fazer por que eu tenho os programas... como os programas são grátis, a gente pode baixar em casa e fazer em casa. Mas 
também a gente tem a opção de vir pra cá, porque tem o apoio dos professores. Porque os professores estarão aqui. Ah! Eu não sei uma coisa, mas tem o professor para mim lá. Isso... o bom é por isso. Por que tem o professor para acolher os problemas que a gente tem. Tipo, a gente não tá só." - educando de programação da escola de nível médio-técnico integrado

Assim como para a autonomia, para a colaboração também percebe-se que é crucial o modo como o educador trata dúvidas e auxilia os educandos na construção do conhecimento. Além disso, é importante que colaboradores e educadores estejam em um nível avançado para resolução de problemas e dúvidas que os educandos venham a ter, para auxiliarem os educandos mais eficazmente e criarem, assim, um vínculo de colaboração.

\subsection{Interesse na Participação}

Ao mostrar interesse em participar de atividades, as pessoas refletem sua preocupação com a qualidade de suas tarefas e produções [Lave e Wenger 1991]. Nos processos observados, os educandos demonstraram o cuidado para obter jogos de boa qualidade (sendo isso em uma passagem de código, uma ilustração ou uma parte da narrativa do jogo). O interesse também foi evidente quando eles apareceram nas reuniões durante as férias escolares ou ficaram nas horas de pós-aula. Os principais aspectos identificados para manter os educandos interessados em participar foram: avaliação periódica, prazos bem definidos, senso de propósito, escolhas democráticas e flexibilidade de papéis.

\subsubsection{Avaliação periódica}

O cenário 1 é um ambiente educacional formal e, portanto, deve respeitar as regras institucionais. Os educandos devem ser classificados, através de notas, para avançar nos anos escolares. Para isso, os educadores avaliam periodicamente os protótipos dos jogos desenvolvidos, também como forma de dar feedback aos educandos para ajudá-los a melhorar, conforme relato de professor:

“Periodicamente a gente faz umas avaliações onde eles tem que apresentar
como está o progresso. Algumas a gente faz com ppt, mas a gente tem evitado
isso. A gente gosta que eles apresentem como está na máquina mesmo. Como
está na engine, como está no illustrator, como está no photoshop. Que eles
mostrem o que conseguiram fazer rodando, pra gente já decidir... ver se o
jogo tem uma cara, porque isso é muito importante. Que eles consigam logo
dá a cara do jogo pra gente ver o que pode ampliar e o que a gente pode
cortar.”- professor coordenador de programação da escola de nível médio-
técnico integrado

\subsubsection{Prazos bem definidos}

Além de avaliações periódicas, percebeu-se mais uma vez, os prazos bem definidos também como propulsor do interesse em participar. No DEMULTS, o número de educandos que participaram das reuniões aumentou à medida que a data final do projeto se aproximava. Os educandos sentiram a necessidade de terminar o jogo no prazo, e tornaram-se altamente participativos e produtivos. Apesar dos efeitos positivos observados nas três categorias de engajamento, é evidente que os prazos devem ser gerenciados cuidadosamente para evitar pressão e estresse, como no relato a seguir:

"Plínio, o único menino do grupo, desenhava com muito cuidado na cartolina, e por isso estava lento. As meninas, mais agitadas, cobravam dele e discutiam ideias de forma um tanto caótica. Uma delas exclamou: Plínio, são 40 
minutos e não 40 horas!!'. Quando o mediador avisou que restavam 20 minutos, as cobranças em cima de Plínio aumentaram e ele esteve a ponto de desistir do desenho por não se sentir capaz de terminar a tempo, mas as meninas não o deixaram desistir." - Thaís, pesquisadora no DEMULTS (seleção)

\subsubsection{Senso de propósito}

$\mathrm{O}$ interesse dos educandos em participar dependeu também fortemente do propósito que poderiam atribuir à atividade de desenvolvimento de jogos. Por exemplo, a oportunidade de levar o jogo a uma competição, indo além de passar de ano na escola, pois, assim, o fato de produzir um jogo digital ganha significado ainda maior do que a obtenção de uma nota ou aprovação em uma disciplina. Consciente desse fator motivacional extra, os educadores no cenário 1 integram os prazos de uma competição estudantil de desenvolvimento de jogos para o calendário escolar, como mostram os relatos do professor coordenador de programação da escola.

"Porque a gente trabalha com o prazo do SBGames. E a gente sempre tem ele como... quando eles se inscrevem, os protótipos vão deixar a gente avaliar como está o progresso deles. Sendo a última etapa do projeto mesmo a submissão para o SBGames." - professor coordenador de programação da escola de nível médio-técnico integrado

No cenário 2 (DEMULTS), os educandos ficaram muito motivados pelo fato de seus colegas que não estavam no projeto, bem como outros amigos e familiares, poderem jogar um jogo desenvolvido por eles, conforme o seguinte relato:

"Em conversa com Vanessa e Luane (educandas designers de Português), Luane perguntou o que é DEMULTS e após explicação de 'sustentável'. Ela demonstrou empolgação e ficou sem palavras para descrever o quanto se sentia por ter a possibilidade de um educando usar o jogo dela na sala de aula." - Diogo, pesquisador no DEMULTS (fase de produção)

\subsubsection{Escolhas democráticas}

Quando os educandos têm permissão para escolher o tema dos jogos, além de possibilitar maior autonomia, eles demonstram maior interesse em participar ativamente. No cenário 2, apesar da imposição de que o jogo deve abordar explicitamente algum conteúdo curricular, os educandos ainda podem escolher os tópicos específicos. Fazer essa escolha envolve a realização de pesquisas sobre conteúdos curriculares e como integrá-los a um jogo. Há engajamento durante a ideação e acredita-se que devido a referências e conhecimentos prévios dos educandos participantes que possuíam um interesse prévio pelo tema do jogo, como explicitado abaixo. Portanto, o contexto democrático no qual os educandos escolhem os temas tende a ser mais engajador que a definição de temas por educadores.

"Cleo esteve atenta e muito participativa, completamente diferente do encontro passado. Fez anotações sobre as fases do jogo e fazia questão de lêlas para o grupo. 'Deixa eu ler o que eu anotei, por favor!' e em outro momento: 'posso ler para revisar?" - Thaís, pesquisadora no DEMULTS (fase de produção)

\subsubsection{Flexibilidade de papéis}

Em ambos os cenários, os educandos podem optar pelo papel de designer gráfico ou programador, de acordo com suas preferências. No cenário 1, não é possível a troca do papel 
assumido ao entrar na escola. No cenário 2, houve casos de educandos que, ao longo do projeto, perderam interesse nas atividades do papel escolhido e começaram a migrar de forma autônoma e/ou assumir outras responsabilidades. Respeitar a autonomia desses educandos e permitir que eles mudassem de papéis foi crucial para manter sua participação. Depois de algum tempo, após mudar o perfil, eles realizaram atividades de design por conta própria e trabalharam de forma autônoma e colaborativa. Assim foi o caso de Julio, que começou como programador (inclusive com experiência previa em programação), mas perdeu o interesse pela atividade. Ele parou de contribuir, usando como argumento a falta de conhecimento do ambiente de programação. Depois de algum tempo, Julio assumiu atividades de design por conta própria e passou a trabalhar de forma independente. Julio acabou criando um jogo separado, e os educadores tiveram que intervir para mediar a integração de seu trabalho ao jogo em desenvolvimento pelo grupo. Apesar das barreiras para trabalhar em colaboração, no final do ciclo Julio ficou feliz em admitir que a versão final do jogo incluiu suas contribuições. Foi o caso também de Cleo, que também optou por ser programadora no início, mas nunca se comprometeu com as atividades de programação e se tornou desinteressada no projeto como um todo. Ela ia às reuniões sem seu computador, ou ela levava-o apenas para assistir vídeos aleatórios, ou às vezes ela se juntava à equipe de design enquanto discutiam alguns aspectos do jogo. Naturalmente, ao interagir com o grupo de design, Cleo começou a contribuir para a concepção da narrativa do jogo e tornou-se uma das educandas mais participativas.

A possibilidade de mudar de papéis pode tornar-se problemática se todos os estudantes decidirem fazer o mesmo. Por outro lado, permitir que os educandos assumam o papel pelo qual se sentem mais atraídos é mais coerente com a filosofia do design participativo, onde as pessoas têm influência significativa na concepção do produto e na tomada de decisões, enquanto aprendem uns com os outros [Bødker et al. 1995].

\section{Desafios do Contexto Escolar}

Ambos os cenários analisados nesta pesquisa foram baseadas na escola. Isto significa que as abordagens inovadoras propostas só podem ir tão longe quanto as regras e legislações institucionais permitem atualmente. Isto é particularmente forte no cenário 1 , onde o desenvolvimento de jogos é uma atividade curricular formal, os educandos devem ser avaliados em datas específicas e as aulas têm locais específicos, duração e regras.

Aulas ou reuniões tradicionais, com palestras e muita teoria sem prática, reforçaram, no cenário 2, a passividade comum dos educandos, à espera de instruções claras sobre o que deveriam ou não fazer para alcançar o que era esperado. Embora possam seguir as instruções, muitas vezes os educandos não refletem sobre o que estão fazendo, pois não precisam tomar decisões conscientes. Um exemplo é mostrado nas notas de campo abaixo, feitas por uma pesquisadora e um educador de programação, respectivamente, sobre a educanda-programadora Vanessa, no cenário 2 (DEMULTS). A primeira passagem refere-se a uma aula de programação, onde o educador demonstrou como usar estruturas de programação condicionais e pediu aos educandos para reproduzir o que ele fazia usando seus computadores. A segunda passagem informa uma reunião posterior quando Vanessa enfrentou a necessidade de usar condicionais ao desenvolver o jogo e não conseguiu alcançar a abstração do conceito.

"Em muitos momentos, os educandos executaram uma repetição mecânica de passos. Vanessa: 'eu até entendi, mas se me pedir pra fazer de novo, eu não faço nada'; 'é muita coisa..."' - Thaís, pesquisadora no DEMULTS (aula de programação) 
"Em alguns momentos Vanessa se destacou, falando de enquanto e quando (estruturas condicionais), meu palpite é que o fato de Vanessa ter participado dos workshops lhe ajudou quando a questionei sobre condições e Adriana como não participou dessa parte não teve, logicamente, a mesma linha de raciocínio. Entretanto, nenhuma das duas alcançaram a condição que eu procurava, if(se), mas Vanessa ficou tentando lembrar, e falava: 'Tu ensinou isso naquele dia lá, mas eu não lembro! É tipo: nahanana isso, nhanahanana o bonequinho se move.' (citação quase literal). As palavras chaves da condição, enquanto ela tentava lembrar, ela ocultava por sonoridades sem sentidos" - Rafael, educador de programação do DEMULTS (fase de produção)

Dessa forma, remonta-se à ineficácia da abordagem de educação bancária, pela qual se pressupõe que o educando irá assimilar tudo o que se expõe, quando na verdade, fica evidente que ele aprende mais significativamente durante a prática em colaboração com seus pares e com educadores.

Outro grande desafio do contexto escolar é a infra-estrutura, que no caso da maioria das escolas públicas brasileiras está longe de ser ideal. No cenário 2 (DEMULTS), no início do projeto não havia computadores suficientes para todos os educandos, então eles tiveram que se agrupar em pares ou grupos de três para as atividades. Isso foi particularmente problemático na fase de oficinas de programação para dar aos educandos subsídios conceituais básicos. Nessa ocasião, uma das pesquisadoras observou:

"No grupo das meninas, Juliete estava mais distante do computador, e por isso também participou bem menos (uma semana atrás, ela teve um computador só para ela e se empenhou bastante nas atividades). Uma das meninas, sobre Juliete: 'ela tá se sentindo excluída, vira o computador pra ela'. Isso impede os educandos de aprender fazendo (e dificilmente eles aprendem programação apenas ouvindo e vendo)." - Thaís, pesquisadora no DEMULTS (aulas)

O cenário 2 também sofria do pequeno intervalo de tempo disponível no horário escolar. Conforme discutido anteriormente, a maioria dos estudantes só trabalhou nos jogos durante as reuniões do projeto. Além disso, muitas reuniões foram canceladas devido a datas comemorativas e eventos escolares, exames, recessos escolares, greves, falta de comunicação com a administração da escola ou indisponibilidade de sala para as atividades. Os intervalos mais longas entre as reuniões tornaram mais difícil reencontrar os educandos e diminuíram seu engajamento.

\section{Modelo de Desenvolvimento Participativo de Jogos Digitais Educacionais no Contexto Escolar}

A análise apresentada na seção anterior subsidiou a construção de um modelo de desenvolvimento de jogos digitais por educandos, apresentado a seguir.

\subsection{Processo}

As etapas do processo desta proposta de modelo são as mesmas do projeto DEMULTS: apresentação, seleção, análise de jogos, ideação, workshops, produção e testes. No entanto, conforme descrição a seguir, algumas mudanças na estrutura dessas etapas são sugeridas. 


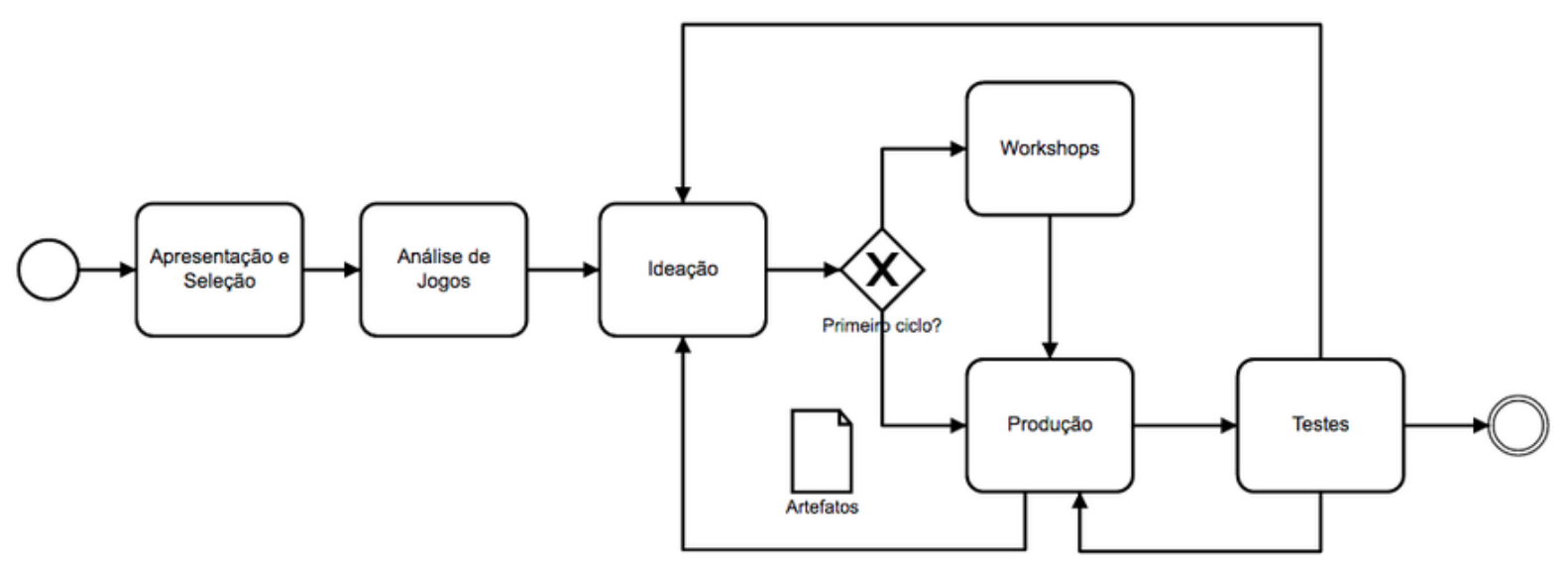

Figura 2: Processo de desenvolvimento de jogos digitais no contexto escolar.

Devido ao tempo, normalmente curto, disponível para o projeto na escola, indica-se que a apresentação e a seleção ocorram juntas, como no DEMULTS. A etapa de análise heurística de jogos digitais educacionais ajuda a compor as referências de jogos dos educandos e iniciar sua formação em noções de game design. Deve-se ter jogos preparados para serem propostos, caso seja percebido que os educandos não possuem muitas referências. Essa etapa ocorre logo após a apresentação e seleção, devido à antecipação da etapa de ideação conforme justificada a seguir.

Entendem-se as voltas da etapa de produção para ideação como naturais nos contextos investigados. Esses retornos e a alta complexidade das ideias de jogos propostas pelos educandos, mesmo após o contato com a ferramenta na etapa de aulas e workshops, demonstram que a etapa de ideação não precisaria vir após aulas e workshops. Por exemplo, na etapa de ideação, ao fazer o brainstorm, no qual os educandos deveriam fazer desenhos apenas para comunicar suas ideias rapidamente, observou-se que faziam artes sofisticadas e gastavam bastante tempo. Portanto, na presente proposta esta etapa de ideação tem o objetivo de explorar o caráter criativo dos participantes, não devendo limitá-lo, deixando para a etapa de produção o momento em que os educandos devem gerenciar suas limitações de tempo disponível e habilidades técnicas necessárias para desenvolver os jogos que idealizaram.

Nos encontros após o brainstorm inicial na etapa de ideação, indica-se o aprofundamento do briefing do jogo por meio da concepção de storyboards. Se necessário, como em jogos que precisem de entendimento de contextos muito específicos, é indicado fazer pesquisas com usuários externos já nesta etapa. Tudo deve ser documentado e armazenado em um repositório virtual. A utilização sistemática dos artefatos mediadores do processo e ferramentas de compartilhamento de arquivos deve ser exposta aos educandos na etapa de ideação. Deve ser criado um quadro de tarefas e apresentado seu funcionamento aos educandos ao término dessa etapa.

Na primeira iteração do processo, entre a ideação e produção há a etapa de workshops. Após essa primeira execução os workshops não devem ser executados outras vezes e o processo ocorre na sequência de ideação-produção-testes. Os workshops devem ter o formato de oficinas práticas, minimizando as aulas expositivas. Além disso, deve-se embasar os conteúdos dos encontros dessa etapa nos conceitos de narrativa, mecânica e regras construídos pelos educandos na etapa de ideação. Por exemplo, a mecânica que já foi escolhida pelos educandos na etapa de ideação, deve ser explorada nos workshops de programação e design, construindo um jogo similar ao idealizado, mas não o mesmo.

Nessa etapa, há a divisão de papéis de atuação: designer e programador. O designer é responsável pelas artes e ilustrações de todos os elementos visuais do jogo. O programador é responsável pelo funcionamento da mecânica e importação de elementos visuais no ambiente de 
programação. Os workshops de game design e introdução a programação têm a participação de todos. Os seguintes (modificação de software e ilustração digital) são para os grupos separados e seguem a mesma execução do DEMULTS.

A etapa de produção consiste no desenvolvimento do jogo por meio do ambiente de programação e ferramenta de ilustração digital, seguido de integração entre as produções dos designers e programadores. Em seu início, é preciso haver uma votação para escolha de um representante de design para auxiliar na importação dos elementos visuais (cenário, obstáculos e atores) pelos educandos de programação e um representante de programação para auxiliar na exportação dos elementos visuais pelos educandos de design. Além disso, nesta etapa é importante dar a possibilidade de alguns educandos migrarem de design e programação para assumirem o papel de atuação de game designer. Game designers são os responsáveis por guiar a ideação na etapa de produção e validar o que se desenvolveu pelos programadores e designers. Eles possuem normalmente os papéis de aprendizagem de inventor e crítico. Importante mencionar que se nenhum educando voluntariamente migrar para o papel de game designer não há intercorrência no processo.

Indica-se que os encontros de produção devem ocorrer da seguinte forma: (i) inicialmente os educandos designers e programadores fazem apresentações das atividades no quadro de tarefas (o que fizeram, o que estão fazendo e o que falta fazer), e no computador na ferramenta de ilustração digital e no ambiente de programação; e (ii) a utilização do tempo do encontro é voltada principalmente para produzir colaborativamente com educandos e educadores.

No início da produção, conforme visto no cenário 1, e também como forma de incentivar o interesse pela ciência, proporcionando uma experiência de iniciação científica no ensino médio, indica-se que se proponha aos educandos participarem de uma competição ou mostra de jogos com o jogo produzido por eles, desde que o jogo seja validado pelos educadores. Almeja-se com isso o engajamento dos educandos ao conceber um sentido mais amplo à prática que estão inseridos. Indica-se que haja uma apresentação de protótipos com prazos a cada duas semanas, sendo o primeiro protótipo com prazo maior, para experenciarem as ferramentas de programação e design.

A etapa de teste inicia-se com a validação dos educadores sobre o protótipo como testável e visa dar embasamento aos educandos designers, programadores e projetistas para tomadas de decisão do projeto. Pode-se testar com usuários externos ao projeto desde ilustrações, para validar entendimento da narrativa, até a jogabilidade. Ao se testar o protótipo com uma versão jogável, mas não necessariamente com toda a narrativa exposta em elementos de interface do jogo, os educandos devem participar dos testes com usuários externos assumindo todas as responsabilidades: moderação, observação e filmagem.

\subsection{Diretrizes para Abordagens Pedagógicas}

Além do modelo proposto, a análise permitiu também gerar uma série de diretrizes pedagógicas para promover o engajamento em contextos de desenvolvimento de jogos em escolas.

\subsubsection{Promoção de contexto democrático}

A partir dos itens "escolhas democráticas" e "possibilidade de troca de papel durante o projeto", identificados na análise como aspectos que levam a autonomia e interesse na participação, pôdese criar a diretriz promoção de contexto democrático. Tal diretriz fundamenta-se nos conceitos de design participativo [Bødker, Grønbæk, Kyng 1995] e engajamento, que necessitam desse contexto democrático para serem aplicados e fomentados, respectivamente.

Indicam-se as seguintes ações docentes para aplicação dessa diretriz: (i) possibilitar escolha do tema, mecânica, narrativa e todos os elementos do jogo pelos educandos, por meio de 
diálogos ou votações. Além da promoção do contexto democrático, esta ação também pode proporcionar mais eficazmente a aprendizagem de conteúdos curriculares, já que espera-se que os educandos sintam-se mais interessados por um tema de sua escolha do que imposto; (ii) possibilitar escolha do local dos encontros pelos educandos, se necessário e quando possibilitado pelo contexto escolar; e (iii) possibilitar troca de papéis de atuação entre designers gráficos, programadores e game designers.

\subsubsection{Interação de educandos e educadores}

A partir dos itens "abordagem pedagógica por perguntas e desafios", "grupos pequenos para facilitar a interação entre educandos e educadores" e "colaborador/educador como gerente até que os educandos ganhem autonomia para se autogerenciarem", identificados na análise como aspectos que levam a autonomia e colaboração, pôde-se criar a diretriz de interação entre educandos e educadores. Tal diretriz fundamenta-se no conceito de Zona de Desenvolvimento Proximal advindo de contribuições da psicologia sócio-histórica [Vygotsky 1989].

Indicam-se as seguintes ações docentes para aplicação dessa diretriz: (i) possibilitar que o educando explore ao máximo suas habilidades para que consiga por si só solucionar problemas; caso não consiga, auxiliá-lo fazendo perguntas, mas não executando nada até que se esgotem as possibilidades do educando chegar às soluções por si só; (ii) auxiliar o educando por meio da indicação de links com tutoriais ou fóruns de resolução de problemas de programação; (iii) auxiliar o educando e depois pedir para ele explicar o que foi feito ou refazer com pequenas alterações, a fim de que o educando construa uma autonomia por meio de independência posterior ao auxílio a partir do entendimento da prática; e (iv) assumir o papel de gerente no início do processo, organizando o grupo com divisão de trabalho, incluindo criação e manutenção de quadro de tarefas, até que os educandos desenvolvam o autogerenciamento das atividades.

Indica-se a seguinte ação gerencial antes da execução do processo para aplicação dessa diretriz: realizar uma formação de capacitação com os educadores em metodologias participativas e nas abordagens pedagógicas baseadas no sociointeracionismo.

\subsubsection{Aspectos práticos de acompanhamento}

A partir dos itens "prazos bem definidos", "execução presencial de tarefas" e "avaliação periódica do jogo", identificados na análise como aspectos que levam a autonomia, colaboração e interesse na participação ativa, pôde-se criar a diretriz de aspectos práticos de acompanhamento. Tal diretriz diz respeito à interação de educadores e educandos, mais especificamente relacionadas ao acompanhamento da produção do jogo.

Indicam-se as seguintes ações docentes para aplicação dessa diretriz: (i) promover atividades e propor tarefas com prazos definidos para o mesmo dia; (ii) exigir dos educandos trabalhos que possam ser executados apenas durante os encontros presenciais do projeto, visando a participação de todos os educandos, já que alguns não possuem infra-estrutura que possibilite o trabalho domiciliar; (iii) definir prazos para avaliação periódica dos jogos, a fim de que os educandos definam o escopo do jogo ponderando suas habilidades técnicas para cumprimento dos prazos; e (iv) promover avaliações periódicas do jogo dos educandos, com banca de avaliação externa ao projeto, por exemplo com docentes que pesquisam ou profissionais de empresas que trabalham com jogos digitais, para que mostrem o que conseguiram fazer rodando no ambiente de programação e no software de ilustração digital.

Além das ações docentes, indica-se também a seguinte característica de arranjo social que deve ser promovido pelo projeto para aplicação desta diretriz: proporção de no máximo 4 
educandos por colaborador ou educador para se ter mais atenção e mais tempo disponível para suporte a cada educando.

\subsubsection{Escolha do ambiente de programação}

A partir do item "ferramenta de programação adequada", identificado na análise como aspecto que leva à autonomia, pôde-se criar a diretriz de escolha do ambiente de programação. Tal diretriz fundamenta-se nos níveis de modificação de software pelo usuário final [Mørch 1997], conceito derivado da programação pelo usuário final [Lieberman et al. 2006], visando um desenvolvimento de habilidades técnicas de programação [Papert e Harel 1991]. Esta diretriz indica que o software escolhido para utilização durante a aplicação do modelo deve possuir boa usabilidade, feedback imediato, linguagem de programação visual e possibilidade de experiência dos três níveis de modificação de software pelo usuário final (customização, integração e extensão) [Mørch 1997].

\subsubsection{Experiência da equipe}

A partir do item "colaboradores que dominem conteúdos curriculares e habilidades técnicas", identificado na análise como aspecto que leva à colaboração, pôde-se criar a diretriz experiência da equipe. Tal diretriz fundamenta-se no conceito de Zona de Desenvolvimento Proximal advindo de contribuições da psicologia sócio-histórica, mais especificamente no nível de desenvolvimento real que o educador/colaborador precisa ter sobre um corpo de conhecimento que está transformando ou buscando entender colaborativamente com outros sujeitos no nível potencial [Vygotsky 1989]. Indica-se a seguinte ação gerencial antes da execução do processo para aplicação dessa diretriz: realizar seleção de colaboradores com entrevista e possibilidade de inserção por um período probatório no projeto, a fim de garantir expertise mínima na área em que irá atuar no projeto (conteúdos curriculares ou habilidades técnicas).

\subsubsection{Fatores externos}

A partir do item "propósitos que vão além do próprio produto e da aprendizagem", identificado na análise como aspecto que leva ao interesse na participação ativa, pôde-se criar a diretriz de fatores externos. Tal diretriz é importante para que os educandos possuam um motivo para se preocuparem com a qualidade do jogo que vá além da aprendizagem e da concepção do jogo em si. Acredita-se que isto corrobora para que se interessem pela participação ativa, pois ao buscarem a qualidade do jogo, se engajam e aprendem conteúdos curriculares e desenvolvem habilidades técnicas.

Indica-se a seguinte ação docente para aplicação dessa diretriz: propor a participação em competições e outros eventos de demonstração de jogos, incluindo os educandos que optarem por isso como autores na submissão do jogo, a fim de promover o interesse na participação a partir de propósitos que vão além do contexto do projeto.

\section{Conclusões}

As principais contribuições deste trabalho foram: (i) identificação de etapas e artefatos de processos de desenvolvimento de jogos digitais educacionais no contexto escolar; (ii) identificação de indicadores e aspectos que promovem engajamento dos educandos nesses processos; e (iii) elaboração de modelo de desenvolvimento participativo de jogos digitais educacionais no contexto escolar com etapas, artefatos, e diretrizes para ações docentes e gerenciais. 
As limitações e contribuições apontam para os seguintes trabalhos futuros: (i) validação do modelo proposto por meio de execução plena de um ciclo no projeto DEMULTS ou em outro contexto similar; (ii) análise comparativa a partir de aplicações do modelo como proposto neste trabalho e com alterações, por exemplo extinguindo a etapa de workshops e permitindo execução ativa de atividades iniciais por colaboradores na etapa de produção; (iii) estudos longitudinais para investigar os aspectos que levam às mudanças de papéis no design participativo; e (iv) estudos mais aprofundados de construcionismo, pensamento computacional e ensino de computação que explorem outros métodos, como investigação de código, para evidenciar aprendizagens de computação.

\section{Agradecimentos}

Agradecemos a todos os participantes da pesquisa (educadores e enducandos), aos gestores das escolas que nos receberam, e à equipe do projeto DEMULTS. Essa pesquisa teve suporte financeiro do CNPq, através de bolsa de mestrado.

\section{Referências}

Blikstein, P. (2008). "Travels in Troy with Freire. Social justice education for teachers: Paulo Freire and the possible dream". p. $205-244$.

Blikstein, P. (2015). "O Movimento Maker e FabLabs na Educação: finalmente realizando o sonho de Freire e Papert, ou mais uma futura história de fracasso?". Keynote Talk. (26th October 2015). Brazilian Conference of Informatics in Education (CBIE). Maceió, Brazil.

Bødker, S.; Grønbæk, K. and Kyng, M. (1995). "Cooperative design: techniques and experiences from the Scandinavian scene". In: Readings in Human-Computer Interaction: Toward the Year 2000. Morgan-Kaufmann. doi: 10.1016/B978-0-08-051574-8.50025-X. [GS Search].

Fredricks, J. A.; Blumenfeld, P. C. and Paris, A. H. (2004). "School engagement: Potential of the concept, state of the evidence". In: Review of educational research, Sage Publications, v. 74, n. 1, p. 59 - 109. doi: 10.3102\%2F00346543074001059. [GS Search].

Freire, P. (2005). "Pedagogia do Oprimido". Paz e Terra. Rio de Janeiro.

Kanthan, G. D/O S. (2011). "Strengthening student engagement in the classroom". Dissertation. National University of Singapore - Faculty of Science.

Jang, H. (2008). "Supporting students' motivation, engagement, and learning during an uninteresting activity". Journal of Educational Psychology, American Psychological Association, v. 100, n. 4. doi: 10.1037/a0012841. [GS Search].

Lanasa, S. M., Cabrera, A. F., Trangsrud, H. (2009). "The construct validity of student engagement: A confirmatory factor analysis approach". In Research in Higher Education, Springer, v. 50, n. 4, p. 315 - 332. doi: 10.1007/s11162-009-9123-1. [GS Search].

Lave, J. and Wenger, E. (1991). "Situated learning: legitimate peripheral participation". Cambridge University Press.

Lieberman, H. et al. (2006). "End-user development: An emerging paradigm". In: End user development, Springer. p. 1 - 8. doi: 10.1007/1-4020-5386-X_1. [GS Search]. 
Mattar, J. (2010). "Games em educação: como os nativos digitais aprendem". São Paulo: Pearson Prentice Hall. Disponível em: http://www.ucs.br/etc/revistas/index.php/conjectura/article/viewFile/334/288. [GS Search].

Meira, L. and Pinheiro, M. (2012). Inovação na escola. In: XI Brazilian Symposium of Games and Digital Enterteinament. Brasília, Brazil. Disponível em: http://base.gamux.com.br/events/2012.11.02SBGames12/proceedings/papers/gamesforchange/g4c-09.pdf. [GS Search].

Morais, D. et al. (2014). Teoria da Atividade para Entendimento de Práticas Humanas no Desenvolvimento Participativo de Jogos. In: XIX Conferência Internacional sobre Informática na Educação. http://www.tise.cl/volumen10/TISE2014/tise2014_submission_287.pdf. [GS Search].

Morais, D. et al. (2015). Storyboards no Desenvolvimento de Jogos Digitais Educacionais por Usuários Finais: Um Relato de Experiência. In: Anais do XXVI Simpósio Brasileiro de Informática na Educação (SBIE 2015). pp. 529-538. doi: 10.5753/cbie.sbie.2015.529. [GS Search].

Morais, D. et al. (2017) Modelo de Desenvolvimento Participativo de Jogos Digitais Educacionais no Contexto Escolar. In: Anais dos Workshops do Congresso Brasileiro de Informática na Educação - Concurso de Teses e Dissertações do Congresso Brasileiro de Informática na Educação (CTD-IE 2017). doi: 10.5753/cbie.wcbie.2017.68. [GS Search].

Mørch, A. (1997). "Three levels of end-user tailoring: Customization, integration, and extension". In: Computers and design in contexto. MIT Press, Cambridge, USA, p. 51 - 76.

Papert, S. and Harel, I. (1991). "Situating constructionism". Constructionism, v. 36, p. 1 - 11. [GS Search].

Parsons, J. and Taylor, L. (2011). "Improving student engagement". Current issues in education, v. 14, n. 1. Disponível em: https://cie.asu.edu/ojs/index.php/cieatasu/article/view/745. [GS Search].

Prensky, M. (2001). "Digital natives, digital immigrants". Part 1. On the horizon, MCB UP Ltd, v. 9, n. 5, p. 1 - 6. doi: 10.1108/10748120110424816. [GS Search].

Reeve, J. et al. (2004). "Enhancing students' engagement by increasing teachers' autonomy support". Motivation and emotion, Springer, v. 28, n. 2, p. 147 - 169. doi: 10.1023/B:MOEM.0000032312.95499.6f. [GS Search].

Sagayadevan, V.; Jeyaraj, S. (2012). "The role of emotional engagement in lecturer-student interaction and the impact on academic outcomes of student achievement and learning". Journal of the Scholarship of Teaching and Learning, v. 12, n. 3, p. 1 - 30. [GS Search].

Vygotsky, L. S. (1989). "Pensamento e linguagem". Ridendo Castigat Mores.

Willekens, R.; Gibson, P. (2010). Hybrid courses and student engagement: opportunities and challenges for community college leaders. International Journal of Educational Leadership Preparation, $\quad$ v. $5, \quad$ n. $1 . \quad$ Disponível em: http://www.ncpeapublications.org/attachments/article/67/m33261.pdf. [GS Search].

Wyeth, P.; Johnson, D. and Ziviani, J. (2013). "Activity, motivation and games for young children". In: ACM. Proceedings of The 9th Australasian Conference on Interactive Entertainment: Matters of Life and Death. doi: https://doi.org/10.1145/2513002.2513025. [GS Search].

Zepke, N.; Leach, L.; Butler, P. (2010) Student engagement: What is it and what influences it. Teaching \& Learning Research Initiative. 
Zin, N. A. M., Jaafar, A. e Yue, W. S. (2009) Digital Game-based learning (DGBL) model and development methodology for teaching history. WSEAS Transactions on Computers. v. 8, n. 2, p.322-333. [GS Search]. 